\title{
Measuring Sustainable Human Resource Management under the new economic era
}

\author{
Yu Xuan ${ }^{1}{ }^{2}$ *, Li Haihong ${ }^{1}$, Ling Miao ${ }^{3}, \mathrm{He} \mathrm{Bin}^{4}$, Wen Jun ${ }^{5}$, Xia Wen Jing ${ }^{6}$ \\ ${ }^{1}$ School of Business Administration, Chongqing Technology and Business University, 400067, Chongqing, China \\ ${ }^{2}$ School of Life Science and Technology, University of Electronic Science and Technology, 610065, Chengdu, China \\ ${ }^{3}$ School of Business, Sichuan University, 610065, Chengdu, China \\ 4. Business School, Harbin University of Commerce, 150028, Harbin, China \\ ${ }^{5}$ HR Department, China Overseas Real Estate, 450000, Zhengzhou, China \\ ${ }^{6}$ School of Public Administration, University of Electronic Science and Technology of China, 610054, Chengdu, China
}

\begin{abstract}
The main feature of the new economic era is the use of network technology, information technology and other economic material means, under the guidance of the age of knowledge, the scientific and technological force as an important productivity of social and economic development. At present, China has entered an era of rapid economic development, and all sectors of society pay more and more attention to human resource management, which provides support for the sustainable development of enterprises. Sustainable human resource management (Sustainable HRM) refers to ideas and practices of human resource management that can bring long-term competitive advantages to organizations, by enabling them to achieve sustainable economic, social, and environmental development. This paper aims to explore the dimension of Sustainable HRM and develop the measure scale and test the construct validation. Based on the United Nations 2030 Sustainable Development Goals (SDGs), the researchers conducted qualitative interviews and also used open questionnaires with 103 corporate managers and employees to obtain their insights on the significance, structure, and ingredients of sustainable HRM under the background of emerging economies. Previous research in the field along with the interview and questionnaire responses were coded and analyzed in order to prepare a preliminary, 25-item scale for measuring sustainable methods of HRM. This initial scale was tested in a study involving 243 participants, and exploratory factor analysis was used to assess the results. The findings shows that sustainable HRM has two dimensions, named sustainable HRM ideas and practice. An adjusted scale was created for measuring two dimensions of sustainable HRM: namely, the ideas ( 7 items) and practices (5 items) of sustainable HRM. This study finds that sustainable HRM has two dimensions: principles or ideas of sustainable HRM and practice of sustainable HRM. The scale is intended to provide a reference point for attempts to expand sustainable HRM, by clarifying directions for research on and development of sustainable HRM. The two-dimensional scale of sustainable HRM developed in this study can prompt companies to pay equal attention to "knowledge" and "action", and to implement the concept of sustainable HRM into HRM policies. Along both dimensions, the reliability and validity of the adjusted scale have reached a good level, and confirmatory factor analysis supports the structural validity of the scale.
\end{abstract}

\section{Introduction}

The new economic, once the stars of the world economy, are now suffering from a complex set of factors that are weakening their growth slightly. What is the future of emerging economies? How should they break through the bottleneck to achieve sustainable development? As of 2015, 193 countries had committed to the United Nations' 17 sustainable development goals (SDGs), and also its proposed 2030 agenda of actions to be undertaken by businesses, governments, and the public in order to achieve those SDGs ${ }^{[1]}$. From a business perspective, the key goal of sustainable development is to build a "sustainable, innovative, and people-oriented" economy and improve employment opportunities, especially for the younger generation and women. The mission of organizations, in this context, is to ensure the health and optimal training of the workforce and to develop the awareness and capabilities needed to create productive employees and active citizens to contribute to society ${ }^{[2]}$. The main feature of the new economic era is the use of network technology, information technology and other economic material means, under the guidance of the age of knowledge, the scientific and technological force as an important productivity of social and economic development. At present, China has entered an era of rapid economic development, and all sectors of society pay more and more attention to human resource management,

\footnotetext{
*Corresponding author: yuxuan_0917@aliyun.com
} 
which provides support for the sustainable development of enterprises. Sustainable HRM can be defined as a planned human resource strategy and practice model that aims to achieve financial, social, and ecological goals, while simultaneously reproducing the human resource base needed for organizations to achieve their goals over the longer term. Thus, sustainable HRM is seen as a new direction in HRM that goes beyond what has been termed strategic $\mathrm{HRM}^{[3]}$.

Research on sustainable HRM has been underway since the $1990 \mathrm{~s}^{[4-6]}$ forming three waves of scholarship. These three waves have foregrounded, respectively, the theoretical sources, the significance and connotations, and the practical requirements of sustainable HRM. Theoretical discussions of sustainable $\mathrm{HRM}^{[7-9]}$ have divided this domain into the three dimensions of economic performance, environmental performance, and social performance, based on the "triple bottom line" principle of economics plus environment plus society. The economic performance dimension involves matters such as economic growth, economic rationality, financial performance, and economic benefits. Meanwhile, the dimension of environmental performance encompasses issues of environmental protection, environmental rationality, and environmental friendliness. Finally, the social performance dimension includes matters of social equity, social rationality, and social responsibility. In the existing literature, empirical research on sustainable HRM is still in its infancy, with relevant studies being scarce and preliminary ${ }^{[10,11]}$. The available research reviews have highlighted the complexity of the field, due to the variety of definitions and approaches applied to Sustainable HRM, contextual factors such as diverse geographical locations, and a lack of shared understandings of the topic in conceptual and empirical research ${ }^{[8,12]}$. By the same token, there is currently no scale for measuring sustainable HRM, and few relevant empirical studies on which such a scale might be based.

In China in particular, companies have carried out a number of practical actions that do not explicitly carry the label of sustainable HRM, but that are equivalent in significance or connotation. Examples include Alibaba's corporate vision of "surviving 102 years" which advocates the concept of "seriously living and working happily", as well as Xiaomi's creation of an enterprise ecological chain. The environmental emphasis of the Chinese government, the revision of China's labor contract law, and the enthusiasm for the " 996 " ${ }^{[1]}$ work schedule for employees of Chinese Internet companies all reflect concerns about sustainable HRM, corporate social responsibility, and environmental responsibility. Against this backdrop, the present research adopts a grounded theory method to explore policies and practices related to sustainable HRM in Chinese enterprises. Using typical enterprises as survey objects, the study is based on semi-structured interviews and open questionnaires. Previous studies in the field as well as the interview and

${ }^{[1]}$ Working from 9am to 9pm, 6 days per week. questionnaire response were coded and analyzed, yielding the initial items to be included on a scale measuring sustainable HRM. Then, through exploratory factor analysis, a sustainable HRM scale that includes 12 items related to the two dimensions of sustainable ideas and sustainable practices was developed. The reliability and validity of the scale are good, suggesting that the instrument can be used as a basic tool for further empirical research.

The remainder of this article is structured as follows. Following a literature review in section 2, we describe, in section 3, how we developed a pre-test scale for sustainable HRM. Section 4 then reports the findings of an empirical test that led to the final version of the scale, with section 5 discussing the significance of these study and the main contributions to research in this area, while also reviewing the implications of our research for management practices, some of the limitations of our study, and the future outlook for additional work in this domain.

\section{Sustainable HRM}

The Brundtland Commission (1987) defined sustainable development as "development that meets the needs of the present without compromising the ability of future generations to meet their own needs". Sustainable development ties together concern for the carrying capacity of natural systems with the social, political, and economic challenges faced by humanity. Sustainability Science is the study of the concepts of sustainable development and environmental science. There is an additional focus on the present generation's responsibility to regenerate, maintain, and improve planetary resources for use by future generations ${ }^{[13]}$. The characteristics of sustainable HRM, in line with the concept of corporate social responsibility, also reflect principles of the Rio Declaration on environment and development; this declaration states that "Human beings are at the center of concerns for sustainable development. They are entitled to a healthy and productive life in harmony with nature"[1]. It is well-established in the current literature that sustainable HRM has a double role: (a) to contribute to implementing sustainable practices in organizations; and (b) to make HRM systems, in particular, sustainable ${ }^{[14]}$.

Sustainable development requires concerted efforts to build an inclusive, sustainable, and resilient future for humanity and the planet. To achieve sustainable development, it is important to coordinate the three core elements or dimensions mentioned previously: economic growth, social inclusion, and environmental protection. These elements are interconnected and vital to the well-being of individuals and society; indeed, eradicating poverty in all its forms and aspects is an indispensable requirement for sustainable development. To this end, it is necessary to promote sustainable, inclusive, and equitable economic growth, creating more opportunities for all; doing so promises to lessen inequality, improve basic living standards, promote equitable social development and inclusion, and promote the integration and preservation of natural resources and ecosystems in strategies for socioeconomic development. Sustainable development in an enterprise is closely related to corporate social re- 
sponsibility, business ethics, and the success of stakeholders. Sustainable HRM aims at simultaneously preserving, regenerating, and developing the economic, environmental, social, and human resources of the organization, thus supporting the very idea of corporate sustainability (CS).

There have been more than two decades of research on sustainable HRM. From the first contributions to the field to today's path breaking work, the relevant research involves a wide range of disciplines. Yet researchers have still not arrived at a shared understanding of what sustainable HRM means, or entails. Different scholars use different terms to describe sustainability and HRM activities, such as the sustainability of human resources ${ }^{[15,16]}$, sustainable work systems ${ }^{[17]}$, sustainable leadership ${ }^{[18]}$, sustainable management of human resources ${ }^{[19,20]}$, sustainable organizations ${ }^{[21]}$, sustainable $\mathrm{HRM}^{[22]}$, green $\mathrm{HRM}^{[23]}$, and HRM based on corporate social responsibility $(\mathrm{CSR})^{[14]}$. Although the labels or rubrics are different, they all point to the need for organizations' HRM to achieve a balance between economic and social benefits. The differences among these frameworks mainly concern the relative importance granted to investments in economic competitiveness, positive social benefits, and ecological benefits.

Several of the available definitions of the field provide useful context here. One definition characterizes sustainable HRM as "the adaptation of HRM practices and strategies that enable [HRM staff] to achieve the financial, ecological and social goals of the organization over a long term horizon, while controlling for negative feedback and unintended side effects" ${ }^{\text {"[3] }}$. Another definition suggests that "Sustainable HRM is the utilization of HR tools to help embed a sustainability strategy in the organization and the creation of an HRM system that contributes to the sustainable performance of the firm. Sustainable HRM creates the skills, motivation, values and trust to achieve a triple bottom line and at the same time ensures the long-term health and sustainability of both the organization's internal and external stakeholders, with policies that reflect equity, development and well-being and help support environmentally friendly practices" ${ }^{[14]}$. Sustainable HRM can also be defined as the creation of HRM systems that help a firm achieve its environmental, social, and economic goals simultaneously, while recognizing that a firm's HRM system itself has significant social impact on its employees and the communities they live in. Hence, there can be inherent tensions in an organization's efforts to balance all of its sustainable HRM objectives ${ }^{[19]}$.

Cross-cutting the areas of sustainable development, environmental management, and HRM, sustainable HRM can be understood as a form of "HRM that not only meets the current needs of enterprises and society but also does not pose a hazard to the satisfaction of their future needs". To conceptualize this form of HRM, a whole new research area is being developed ${ }^{[24]}$, according to which sustainable HRM is a human resource strategy and practice model that aims to achieve financial, social, and ecological goals, while simultaneously reproducing the human resource base over the longer term ${ }^{[25]}$. The academic community now recognizes the central position of
HRM in sustainable development organizations, with analysts now advocating improving the economic performance, environmental performance, and social performance of organizations through three key channels: innovation management, environmental management, and cultural diversity management ${ }^{[26]}$. In short, sustainable HRM can be defined as a series of HRM concepts and practices that help organizations to obtain long-term competitive advantages. The focus is on finding a balance between economic performance, environmental performance, and social performance. Through this balance, internal human resources (that is, sources of high-quality labor) become more sustainable, while the continued output of external benefits (that is, the re-creation of labor value) is also ensured; thus both the internal and external benefits of the organization are maximized. What needs to be emphasized in this context is that sustainable HRM must achieve sustainable, orderly, stable, and coordinated development of HRM activities under the three constraints of economy, environment, and society, so that human resources continue to support the sustainable development goals of individuals, organizations, and society, and ultimately boost the sustainability of the entire HRM system.

Sustainable HRM thus highlights the importance of HR practices for organizational outcomes that go beyond financial performance ${ }^{[27]}$. One way of understanding the links between sustainability and HRM is via Enhert and Herry's Paradox theory ${ }^{[28]}$. This theory points to paradoxical choices affecting the balance between resources consumed and resources produced, arising from the pressure for performance and results that can itself be a source of transformation and innovation. Jepsen and Grob(2015) demonstrated in their study that applying a sustainable selection process in the organization shows not only a balanced commitment to the planet, people, and profits, but may serve as a competitive differentiator in the employee marketplace, drawing top talent to the organization $^{[29]}$. In that same connection, training is an important method for developing the capacity and skill of employees in the enterprise; hence training practices can be retooled to achieve the goal of the sustainable human resource regeneration while also improving the organization's overall competency. Career planning for employees, too, plays an important role in employees' long-term development in an organization, as do performance evaluations that factor in CSR behavior and volunteering, designed to enhance employee growth as well as corporate social responsibility more generally. In sum, the previous literature in the field suggests that sustainable HRM can be defined as sets of HRM ideas and practices that help organizations obtain long-term competitive advantages.

\section{Developing A Pre-test Scale For Sustainable HRM}

Since the research on sustainable HRM is still in an emerging stage, it is not feasible to summarize the evaluation criteria extracted from the interviews so as to map those criteria accurately onto the connotations and es- 
sence of the concept. Instead, to develop and verify a scale for measuring sustainable HRM, we used the scale preparation method discussed in Churchill (1979), which is carried out in three stages: (1) collecting original data through qualitative interviews and open questionnaires; (2) encoding and sorting the collected original data to create a closed questionnaire; and (3) using this preliminary questionnaire to conduct a small-scale pre-test, and then performing qualitative and quantitative adjustment to the questionnaire to generate a formal scale.

\subsection{Existing Literature for Sustainable HRM Measurement}

In order to analyze the content structure of the construct as accurately as possible, this study reviews the papers on sustainable HRM that represent key concepts and best practices in the field. Although there have been theoretical discussions on the dimensions of sustainable $\operatorname{HRM}^{[7,13]}$, there is currently no specialized scale for sustainable HRM. Wehling et al.(2016) suggest five core dimensions of sustainable HRM practices: rationale (motivations, triggers, and benefits), conceptual framework (models and terminology), direction (functional responsibility and hierarchical accountability), transfer (implementation mechanisms and knowledge transfer), and evaluation (awards, bench marking, metrics, and content of reports) ${ }^{[7]}$. Kainzbauer and Rungruang(2019) summarized the first approach used to harness sustainable HRM to enhance organizational sustainability ${ }^{[8]}$; the approach focuses on practices that help to influence people in developing sustainable attitudes and behaviors. Examples of such practices include attracting talent via the sustainability commitment of the organization; training employees in knowledge acquisition and capability development supporting sustainability goals; integrating sustainability goals into practices of assessment and compensation; building an organizational culture that encourages the development of sustainability practices; creating an organizational support system that fosters corporate sustainability behaviors; implementing diversity initiatives; and using internal communication to strengthen the focus on corporate sustainability ${ }^{[14]}$. A second approach to harnessing sustainable HRM involves incorporating sustainability principles into HRM practices $^{[8,30,31]}$. Gollan $(2000)$ conducted one of the pioneering studies in this area; the study presented the sustainability concept in the context of HRM and showed that organizational sustainability must be based on acknowledgement, recognition, and development of the capacities of employees ${ }^{[15]}$. If these issues are not considered, it is highly likely that an organization will lose talent to other, more sustainability-oriented enterprises.

In the literature, there are scales that use concepts related to sustainable HRM, such as scales for measuring the extent to which "organizations use resources for issues related to sustainable development", and the degree to which "HRM is embedded in goals related to corporate social responsibility". In our review of the available measures, we found two options for a scale for measuring sustainable HRM. The first option is (i) the six-item scale by Orlitzky and Swanson (2006), which includes items related to the extent to which the employment organization devotes resources to the following issues and practices: sustainability-related issues in recruitment and selection $^{[32]}$; training to promote sustainability as a core organizational value; training to develop employees' skills in receptive stakeholder engagement and communication; developing metrics to compensate employee social performance in the form of promotions, performance appraisals, rewards, and monetary compensation.

The second option is (ii) an index based on "the role of HR in corporate sustainability"(CIPD,2013). This index includes 10 possible HRM practices that can be used to embed corporate sustainability (CS) and corporate social responsibility (CSR) objectives in an organization via HRM. Relevant practices include, for example, leadership and management training on $\mathrm{CS}$ issues; policies to improve employee well-being being actively championed by senior management; internal publicity campaigns to raise awareness of CSR issues; employee induction programs that emphasize responsible and sustainable values; employee champions of CS and CSR; recruitment and selection criteria that look for responsible values or behaviors in prospective employees; leadership and management training on CSR issues; organization-wide training to develop responsible and sustainable behavior; employee performance assessment or appraisals that include CSR objectives; job descriptions with CS and CSR objectives; incentives or rewards that recognize responsible and sustainable behavior.

Scale (i) includes 6 items, including HRM recruitment, values, training, performance and compensation, and promotion $^{[32]}$. By contrast, scale (ii), used to gauge the role of HR in advancing corporate sustainability, has 10 items(CIPD,2013). Another instrument, used to measure HR's role in social responsibility and sustainability in the context of the Society of Human Resource Management (SHRM) Foundation includes 4 items $^{[14]}$. Yet another study ${ }^{[33]}$ analyzes sustainable HR practices in terms of competence development and employee relations dimensions. The measure for competence development includes 5 items and the measure for employee relations has 4 items. However, this instrument is not properly dimensioned, and the scale items are different.

In short, because there is no existing scale for the measurement of sustainable HRM, whether the focus is on the organization's level of sustainable development or a related issue, such as the degree to which HRM is embedded in corporate social responsibility objectives or the extent of the SHRM Foundation's development of employee competence and employee relations, it is necessary to create design a scale suitable for measuring sustainable HRM. In the studies mentioned, the structure of the scales used is not clear, and the items are quite different. Hence it is necessary to explore the dimensional structure of sustainable HRM, and to identify, cluster, and adjust the items required for an appropriate instrument. To this end, the literature review summarized key concepts and dimensions of sustainable HRM. At the same time, to address the dual concerns of organizations and their employees, we select from each study the key points 
and specific practical activities directly related to sustainable HRM. This phase of our research involved several rounds of discussion and modification, on the basis of which we refined the specific evaluation items, and prepared a preliminary version of the sustainable HRM scale.

\subsection{Semi-structured Interviews and Expert Discussions}

Some of the items in the initial scale obtained on the basis of the literature review are underdeveloped and do not necessarily conform to the actual practice of sustainable HRM in Chinese enterprises. As a result, this study adopts the methods described in the following subsections to conduct qualitative research in this domain. It uses these methods to explore the meaning and dimensions of sustainable HRM in the Chinese context, and to adjust the initial scale accordingly.

\subsubsection{Question Seminars with Managers}

We conducted interviews with participating companies through the "Corporate Social Responsibility and Sustainable Development Forum". A total of 15 business managers were asked about the characteristics of sustainable HRM and how they evaluated sustainable HRM. Around this theme, participants were invited to list specific practical measures of enterprises. Before the interview, the researcher introduced the purpose of this study, the expected content of the interview, and the arrangements that had been made to ensure privacy. Consent by the 15 business managers interviewed was obtained, and the concept of sustainable HRM itself was clarified, in order to obtain the most relevant information vis-à-vis the enterprises' actual practices. The average interview time was about 30 minutes. In the interview, the researchers conducted interactive dialogues flexibly according to an interview outline prepared in advance. At the end of the interview, the researcher converted the recording into text and performed content analysis on the resulting transcript. Overlapping concepts of sustainable HRM could thus be pruned away, and redundant or irrelevant scale items could be eliminated. We found that the 8 items, which were initially precipitated from the literature review, warranted inclusion in the scale and were in line with the interview results. Further, because the specific practical terms used in the interviews differed from those proposed by researchers, we adjusted the description of the measurement items for later investigation.

\subsubsection{In-depth Interviews with Managers and Employees}

To get managers' and employees' perspectives on sustainable HRM, we conducted in-depth interviews with total 42 interviewees from 10 high-tech enterprises in Sichuan and Chongqing, in the southwest of China, including 12 corporate executives, 8 human resources managers, 10 line managers, and 12 employees. We then discussed the literature review along with our analyses of the interview results, with the goal of avoiding any gaps in the data while excluding items that do not belong to the domain of sustainable HRM, merging together consistent or similar items, and redressing problems with fuzzy semantics. Through the interviews, we extracted topics that had not come up in the literature, such as "double channels for professional development for R \& D personnel" and "personalized training for employees".

\subsubsection{Collection of Data about Critical Events Involving Sustainable HRM in the Companies}

Using the 17 goals included in the United Nations' list of Sustainable Development Goals (SDGs) for 2030, at the beginning of the open questionnaire, we listed these goals and asked the participants to provide details about the practices that are helpful to the achievement of these goals in their company. We asked business managers about specific HRM practices that are conducive to achieving these SDGs. Further, having distributed the open questionnaire to on-the-job MBA students from Chongqing Technology and Business University, we collected 46 of the questionnaires, from which we obtained data about critical events involving sustainable HRM practices in the companies where the respondents worked. Having classified these practices into various categories, we imported materials into NVIVO 11 software and adopted grounded theory coding methods to obtain a total of 162 sustainable HRM philosophies and principles and 279 sustainable HRM practice items. We merged items based on similarities.

\subsubsection{Expert Screening of the Items}

After selecting the relevant measurement items from the previous research via the above-mentioned thematic seminars, individual in-depth interviews, and classifications of key events, we compiled a list of scale items, and also an initial item pool of critical events. In order to conduct a more detailed analysis of the applicability of these entries, five experts were invited to participate in the further screening of these items. These experts read, analyzed, and screened the items independently, according to their respective professional backgrounds and research emphases. After repeated discussions, the pre-test scale for measuring sustainable HRM in the context of China was obtained; the scale contained 25 items in total, designed to be used for the follow-up large-sample survey. Finally, before the formal questionnaire survey was developed, 30 employees of an enterprise in Sichuan province were invited to fill in the revised questionnaire. The wording for each item was adjusted according to the feedback received at this stage.

\section{Developing The Scale For Sustainable HRM}

Screening items for measuring instruments should follow the principles of selectivity, sensitivity, good representativeness, independence, and good discrimination, and should consider the overall acceptability of the items. 
With these criteria in mind, the discrete degree method, correlation coefficient method, factor analysis method, discrimination analysis method, Cronbach's $\alpha$ method, and retest reliability method are used to analyze the results and filter the final items to be included in the scale.

\subsection{Procedure and Participants}

We randomly selected 300 enterprises in 6 provinces, municipalities, and autonomous regions in China, including Sichuan, Chongqing, Guangdong, Hunan, Hubei, and Beijing, as survey objects. We distributed questionnaires to corporate executives and human resource managers. The questionnaires were scored on a 5 Likert scale, whereby total agreement is 5 , agreement is 4 , uncertainty is 3 , disagreement is 2 , and total disagreement is 1 . A total of 274 questionnaires were collected; incomplete questionnaires, as well as questionnaires filled out with the same answers repeatedly, were removed to ensure quality control. Ultimately, 243 samples were verified. Approximately half of the samples were randomly selected (122 completed surveys that had been assigned odd numbers), and each item was analyzed according to the previously described screening methods using SPSS statistical software. On the basis of these procedures, 19 valid items were finally selected to establish a sustainable HRM scale. The second step is the evaluation of the scale. The remaining half of the sample (121 completed surveys that had been assigned even numbers) was used for confirmatory factor analysis via AMOS24.0 statistical software. In this analysis, the valid items selected through the previous procedure are renumbered. In the new sequence, the load of each item on the corresponding factor in the confirmatory factor analysis determines how the items are numbered. More precisely, they are numbered in descending order, i.e., with the highest-load items coming first.

The evaluation procedures we used at this stage include the following:

- Structural dimension assessment: According to the results of exploratory factor analysis, we propose a testable two-dimensional model to test whether the established factor model is the best theoretical model. AMOS24.0 statistical software was used to compare the advantages and disadvantages of different models using confirmatory factor analysis. According to the previous research results and corresponding theoretical basis, the factor model of the existing scale was compared to the factor model of the revised scale.

- Reliability evaluation: In order to evaluate the reliability of the sustainable HRM dimensions, the structural reliability of each factor was calculated. The structural reliability measures the internal consistency of the scale.

- Validity evaluation: In the process of using the developed scale for testing, we determined the validity level of the scale by examining the content validity, construct validity, discriminant validity, and validity associated with the standard.

\subsection{Empirical Test of the Sustainable HRM Scale}

\subsubsection{Item Purification}

In this study, a single overall correlation coefficient (CITC) was introduced to conduct a homogeneity test, which was used as a method for the purification of items in the sustainable HRM scale. According to Nunnally, the CITC index should not be less than 0.5 . The result shows that that "F21" is irrelevant to the population $(\mathrm{C} 1 \mathrm{TC}=0.345<0.5)$. Therefore, this item should be excluded.

\subsubsection{Exploratory Factor Analysis}

\section{a) Sample Object Description}

Among the 122 oddly numbered questionnaires, $49.8 \%$ were completed by males and $53.3 \%$ by females. As for education levels, "college degree or below" accounted for $17.2 \%$ of the responses, "undergraduate degree" accounted for $47.5 \%$, and "postgraduate or above" accounted for $35.2 \%$." In terms of job categories, "general staff" accounted for $48.4 \%$ of the responses, "junior managers" accounted for $16.4 \%$, "middle level managers" accounted for $18.9 \%$, and "senior manager" accounted for $16.4 \%$. With respect to organization type, "private enterprises" accounted for $49.2 \%$ of the responses, "state-owned enterprises" accounted for $27 \%$, "foreign-funded enterprises" accounted for 6.6\%, "Chinese-foreign joint ventures" accounted for $12.3 \%$, and "mixed-ownership enterprises" accounted for 4.9\%. Finally, with respect to industry type, "manufacturing" accounted for $40.1 \%$ of the responses, "service industry" accounted for $25.4 \%$, "agriculture, forestry and animal cultivation" accounted for $14.8 \%$, and "other" accounted for $19.7 \%$.

b) KMO and Bartlett's Test.

In order to test whether the survey data is suitable for factor analysis, a Bartlett spherical test was performed on the data. The test value is $2617.76(\mathrm{P}<0.000)$, which indicates the possibility that factors were shared among the items. At the same time, the sample KMO value is 0.938 , indicating that the data sample is suitable for factor analysis.

\section{c) Factor Extraction}

In this study, principal component analysis and the maximum variance method were used to extract factors, and the criterion for factor selection was a characteristic value greater than 1. Factors and items that met this standard were retained, and items with a factor load value less than 0.5 , as well as items with multiple cross loads, were deleted. After each deletion of unqualified items, the exploratory factor analysis step was performed again until the data standard of factor analysis was met, i.e., the variance interpretation level was higher than $50 \%$, the factor load was greater than 0.5 , and the factor structure was clear. 
First, exploratory factor analysis was conducted on the sample data of 24 items, and a total of 3 factors were extracted (the characteristic value of the fourth factor was less than 1), which explained $69.478 \%$ of the variation. The characteristic value of factor 1 is 6.979 and the variance contribution rate is $29.078 \%$; the characteristic value of factor 2 is 6.220 and the variance contribution rate is $25.918 \%$; and the characteristic value of factor 3 is 3.476 , while the variance contribution rate is $14.483 \%$. Meanwhile, we delete the items with serious cross-load phenomenon(two or three factor loading are over 0.4), i.e.F4,F7,F9, F10,F11, F12,F14,F15,F16,F18 and F19.

A second exploratory factor analysis was then performed on the remaining 13 items. The KMO (value 0.913 ) and Bartlett test (approximate chi-square = 1236.295; $\mathrm{Df}=78 ; \mathrm{P}<0.00)$ met the standard; using these measures, we extracted two factors with eigenvalues greater than 1 , and the total variance interpretation rate was $69.624 \%$. At this stage, we also deleted the items with serious cross-load phenomena, namely F20. In addition, the common factor steep slope diagram shows that the connection between the first two points is relatively steep, while the line between the third point is relatively flat. This pattern indicates that it is advisable to retain the two factors.

Finally, a third exploratory factor analysis was performed on the remaining 12 items. The KMO (value 0.914) and Bartlett test (approximate chi-square = 1177.642; $\mathrm{Df}=66 ; \mathrm{P}<0.00)$ met the standard, and we thus extracted two factors with eigenvalues greater than 1 . The total variance interpretation rate was $65.396 \%$.

As shown in Table 1, a clear two-factor structure for measuring sustainable HRM was obtained, and the factor load of the corresponding items of each factor was greater than 0.5. Among them, the eigenvalue of factor 1 is 7.345; this value explains $61.209 \%$ of the variation, and encompasses 7 items: F1, F3, F5, F6, F2, F8, and F13. Since this dimension aims to describe the concept of sustainable HRM, we named it the dimension of "sustainable HRM ideas" (hereafter referred to as "SHRMI"). The eigenvalue of factor 2 is 1.346 , which explains $11.218 \%$ of the variation. This value contains 5 items: F24, F23,F17,F22 and F25. Since this dimension is designed to be reflected in measures of sustainable HRM, we named it the dimension of "sustainable HRM practices" (hereafter referred to as "SHRMP"

Table 1. Results of the exploratory factor analysis of the last round (after rotation)

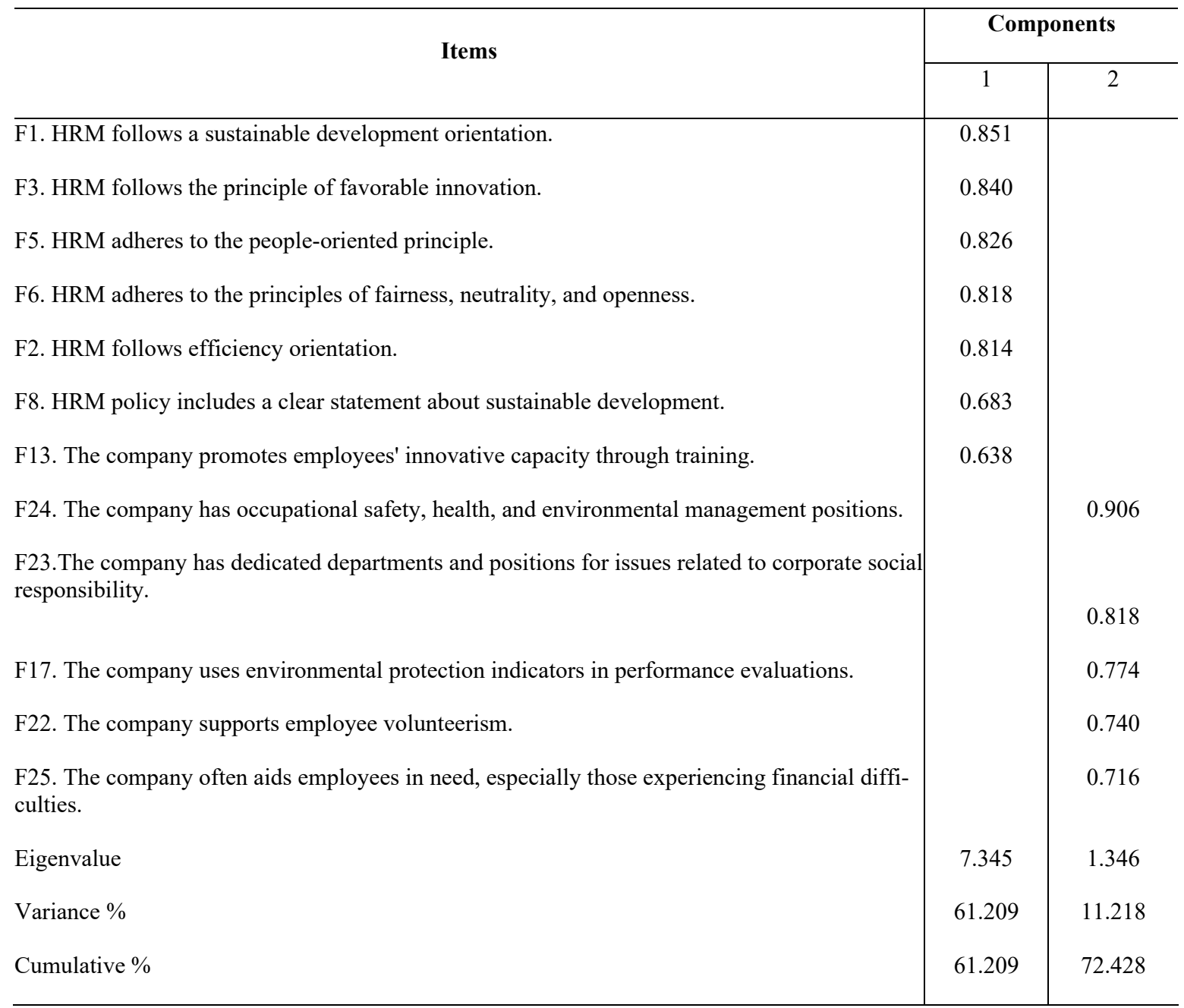




\subsubsection{Confirmatory Factor Analysis}

The remaining half of the sample (the 121 evenly numbered questionnaires) was used to further test whether the two-dimensional structure obtained by exploratory factor analysis can be supported by other sample data.

\section{a) Sample Description}

Among the 121 evenly numbered questionnaires, 56.2\% were submitted by males and $43.8 \%$ by females. In terms of education level, "college degree or below" accounted for $17.4 \%$ of the responses, "undergraduate degree" accounted for $43.8 \%$, and "postgraduate or above" accounted for $38.8 \%$. With respect to job categories, "general staff" accounted for $43.0 \%$ of the responses, "junior managers" accounted for $32.2 \%$, "middle level managers" accounted for $10.7 \%$, and "senior manager" accounted for $14.0 \%$. In terms of organization type, "private enterprises" accounted for $50.4 \%$ of the responses, "state-owned enterprises" accounted for $24.0 \%$, "foreign-funded enterprises" accounted for 5.0\%, "Chinese-foreign joint ventures" accounted for $13.2 \%$, and "mixed-ownership enterprises" accounted for 7.4\%. With respect to industry type, "manufacturing" accounted for $35.6 \%$ of the responses, "service industry" accounted for $26.4 \%$, "agriculture, forestry and animal cultivation" accounted for $14.9 \%$, and "other" accounted for $23.1 \%$.

\section{b) Confirmatory Factor Analysis}

Confirmatory factor analysis is used to detect whether the relationship between a factor and its corresponding items conforms to the hypothesis and posited theoretical relationships, and to verify the content structure of the sustainable human resource management scale obtained via exploratory factor analysis. According to previous studies $^{[34,35]}$, the index standard with respect to the fitting degree of the confirmatory factor analysis model is $\chi 2 / \mathrm{df}<3, \mathrm{RMSEA}<0.08, \mathrm{CFI}>0.9$, TLI $>0.9$, indicating that the model fitting degree is good.

The robust maximum likelihood estimation method was used to validate the model. The results of the first-order confirmatory factor analysis show that the content structure of the two-dimension scale for sustainable human resource management fits well. At the same time, the standardized factor load of the items corresponding to the two factors reached the significance level, and the coefficient value was greater than or equal to 0.63 (as shown in Figure 1), indicating that the model has a good adaptability.

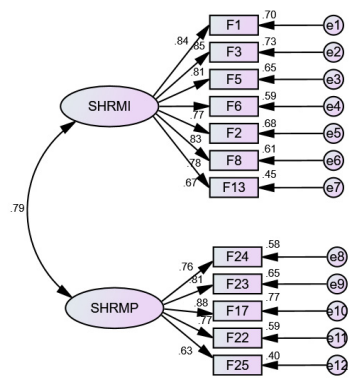

Figure 1. Confirmatory factor analysis results $(\mathrm{N}=121)$
In order to further test the conceptual dimension of sustainable human resource management, this study also proposed two competitive models: (1) M1, a single factor model, combining 19 projects into one potential factor; and (2) M2, a two-factor model, with SHRMI merged into one potential factor and SHRMP merged into another potential factor. As shown in Table 2, the fitting effect of M1 is worse than that of the M2 when the two models are used to analyze the results obtained by exploratory factor analysis. Therefore, this study assumes that the model fitting degree is ideal, and that the fitting degree between the model and the observed data is good.

Table 2. Results of confirmatory factor analysis

\begin{tabular}{ccccccc}
\hline Model & $\chi \mathbf{2} / \mathbf{d f}$ & RMSEA & GFI & AGFI & CFI & TLI \\
\hline One-factor & 3.290 & 0.138 & 0.812 & 0.707 & 0.879 & 0.841 \\
& & & & & & \\
Two-factor & 1.458 & 0.062 & 0.914 & 0.864 & 0.976 & 0.968 \\
\hline
\end{tabular}

\subsubsection{Reliability Analysis}

Furthermore, the reliability of the two factors is analysed. According to the standards adopted in previous exploratory studies, if the Cronbach's $\alpha$ internal consistency values for the two subscales of sustainable HRM and the overall scale are $0.933,0.907$ and 0.941 , respectively, then the requirements for high reliability have been met. As shown in Table 3, all of these Cronbach's $\alpha$ values are greater than 0.8 , indicating that the scale designed in this study has a high reliability.

Table 3. Reliability analysis

\begin{tabular}{c|c|c|c|c}
\hline Dimension & $\begin{array}{c}\text { Cronbach's } \\
\boldsymbol{\alpha}\end{array}$ & CR & AVE & $\begin{array}{c}\text { Square } \\
\text { Root of } \\
\text { AVE }\end{array}$ \\
\hline SHRMI & 0.933 & 0.918 & 0.617 & 0.787 \\
\hline SHRMP & 0.907 & 0.894 & 0.630 & 0.794 \\
\hline Total scale & 0.941 & 0.951 & 0.622 & 0.789 \\
\hline
\end{tabular}

\subsubsection{Validity Analysis}

In this study, the validity of the scale was tested in terms of both content validity and structure validity. On the one hand, the three criteria of content validity were as follows: (i) the measurement items fully and accurately reflected the objective construct; (ii) the measurement indicators were representative; and (iii) the questionnaire measures had the appropriate form. This study adopted literature analysis and interview methods to establish the questionnaire contents. We conducted in-depth interviews with 12 corporate executives, 8 human resources man- 
agers, 10 business managers, and 12 employees in 10 high-tech enterprises in Chengdu and Chongqing, and the items emerging from responses were revised to ensure good content validity of the scale.

On the other hand, composite reliability (CR) and average variance extracted (AVE) were used to test the structural validity of the scale ${ }^{[36]}$. The results showed that the combined reliability of the two factors was 0.894 and 0.918 , higher than the standard of 0.7 proposed by Hair $(1998)^{[37]}$, indicating that the construct validity of the scale was good. The AVE values of the overall scale and subscale were between 0.617 and 0.630 ; in both cases, these values are higher than the standard of 0.5 recommended by Bagozzi (1998) ${ }^{[38]}$. At the same time, the load values of all factors were greater than 0.5 and reached the significance level, indicating that the scale had good convergence validity. The square root of AVE of each factor is 0.787 and 0.794 , which is greater than the standard correlation value of each factor, indicating that this scale has a good discriminant validity.

\section{Conclusion And Future Research}

\subsection{Research Contributions and Management Implications}

This study examines concepts of sustainable HRM in the new era. Compared to strategic HRM, sustainable HRM places more emphasis on maintaining and developing the human resource base of the organization. With the aim of avoiding negative impacts, sustainable HRM works to balance the differences between organizations' economic goals and effects, on the one hand, and sustainable development, on the other hand. The present research adopts a grounded theory method, selects Chinese companies as survey objects, conducts semi-structured interviews, explores the implementation status of sustainable HRM policies in enterprises, and suggests a model for sustainable HRM for different scenarios in China. The scale is intended to provide a reference point for attempts to expand sustainable HRM, by clarifying directions for research on and development of sustainable HRM. The two-dimensional scale of sustainable HRM developed in this study can prompt companies to pay equal attention to "knowledge" and "action", and to implement the concept of sustainable HRM into HRM policies. It also highlights how HRM practices can be used to help enterprises achieve sustainable competitive advantages and sustainable development.

To achieve the UN's SDGs, the business world can play a very important role. In this context, sustainable HRM in corporations can make a big difference. Whereas the study's implication for theory is that the scale of sustainable HRM confirms two dimensions of sustainable ideas and practices in the business world, the study's implication for practice is that enterprise can use sustainable HRM to achieve long-term competitive advantage.

\subsection{Limitations of Research and Future Outlook}

The study has some limitations. First, the self-reports regarding sustainable HRM on the part of managers may be influenced by the social desirability effect. A second limitation is that all the data were collected from mainland China, potentially limiting the generalizability of the results.

to other cultures. A third limitation is that validity criteria for sustainable HRM are not included in the research. In future research, sustainable competitive advantage could be used as a criterion to test the validity of sustainable HRM. Antecedents of sustainable HRM, such as the study of sustainable leadership and environmentally oriented pressure from stakeholders, as well as evidence concerning the results of sustainable HRM, such as overall HRM performance, can be incorporated into future theoretical and empirical research in this domain.

\section{Acknowledgement}

This work was supported by China Postdoctoral Science Foundation "Sustainable Human Resource Management: A Tracking Study of Influencing Factors and Effects" (2020M673191) and Youth Project of National Natural Science Foundation of China "The formation of high-quality connections in virtual teams and its impact on team and individual creativity: A cross-level tracking study" (71802033).

\section{References}

1. United Nations. Documentation, Reference, Terminology Section. Environment and Development[M]. UN, 1992.

2. Chams N, García-Blandón J. On the importance of sustainable human resource management for the adoption of sustainable development goals $[\mathrm{J}]$. Resources, Conservation and Recycling, 2019, 141: 109-122.

3. Kramar R. Beyond strategic human resource management: is sustainable human resource management the next approach?[J]. The international journal of human resource management, 2014, 25(8): 1069-1089.

4. Elkington J. Towards the sustainable corporation: Win-win-win business strategies for sustainable development[J]. California management review, 1994, 36(2): 90-100.

5. Jabbour C J C, Santos F C A. The central role of human resource management in the search for sustainable organizations[J]. The International Journal of Human Resource Management, 2008, 19(12): 2133-2154.

6. Ehnert I, Parsa S, Roper I, et al. Reporting on sustainability and HRM: A comparative study of sustainability reporting practices by the world's largest companies[J]. The International Journal of Human Resource Management, 2016, 27(1): 88-108. 
7. Wagner M. Environmental management activities and sustainable HRM in German manufacturing firms-incidence, determinants, and outcomes[J]. German Journal of Human Resource Management, 2011, 25(2): 157-177.

8. Ehnert I. Sustainability and Human Resource Management Developing Sustainable Business Organizations[M]. Springer, 2014.

9. De Prins P, Van Beirendonck L, De Vos A, et al. Sustainable HRM: Bridging theory and practice through the Respect Openness Continuity (ROC)'-model[J]. Management revue, 2014: 263-284.

10. Aguinis H, Glavas A. What we know and don't know about corporate social responsibility: A review and research agenda[J]. Journal of management, 2012, 38(4): 932-968.

11. Jackson S E, Schuler R S, Jiang K. An aspirational framework for strategic human resource management[J]. Academy of Management Annals, 2014, 8(1): 1-56.

12. Macke J, Genari D. Systematic literature review on sustainable human resource management[J]. Journal of cleaner production, 2019, 208: 806-815.

13. Finn D. Our uncertain future: Can good planning create sustainable communities?[M]. University of Illinois at Urbana-Champaign, 2009.

14. Cohen E, Taylor S, Muller-Camen M. HRM's role in corporate social and environmental sustainability[J]. SHRM report, 2012, 1: 1-16.

15. Gollan P J. Hureman sources, capabilities and sustainability[C]//Internationalisationde la gestion des ressources humaines?. 2000.

16. Wikhamn W. Innovation, sustainable HRM and customer satisfaction[J]. International Journal of Hospitality Management, 2019, 76: 102-110.

17. Creating sustainable work systems: emerging perspectives and practice[M]. Psychology Press, 2002.

18. Avery G. Leadership for sustainable futures: Achieving success in a competitive world[M]. Edward Elgar Publishing, 2005.

19. Ehnert I. Sustainability Issues in Human Resource Management: Linkages, theoretical approaches, and outlines for an emerging field[C]//21st EIASM Workshop on SHRM. 2006: 30-31.

20. Ehnert I. Sustainability and HRM: A model and suggestions for future research[M]/The future of employment relations. Palgrave Macmillan, London, 2011.

21. Morrison J L. Organizational Change for Corporate Sustainability-A Guide for Leaders and Change Agents of the Future[J]. Journal of Education for Business, 2003, 79(2): 124.

22. Mariappanadar S. The harm indicators of negative externality of efficiency focused organizational practices $[\mathrm{J}]$. International Journal of Social Economics, 2012, 39(3-4), 209-220

23. Bombiak E, Marciniuk-Kluska A. Green human resource management as a tool for the sustainable development of enterprises: Polish young company experience[J]. Sustainability, 2018, 10(6): 1739.

24. Jackson S E, Renwick D W S, Jabbour C J C, et al. State-of-the-art and future directions for green human resource management: Introduction to the special issue[J]. German Journal of Human Resource Management, 2011, 25(2): 99-116.

25. Kramar R. Beyond strategic human resource management: is sustainable human resource management the next approach?[J]. The international journal of human resource management, 2014, 25(8): 1069-1089.

26. Jackson S E, Renwick D W S, Jabbour C J C, et al. State-of-the-art and future directions for green human resource management: Introduction to the special issue $[\mathrm{J}]$. German Journal of Human Resource Management, 2011, 25(2): 99-116.

27. De Prins P, De Vos A, Van Beirendonck L, et al. Sustainable HRM for sustainable careers: Introducing the 'Respect Openness Continuity (ROC)'model[M]//Handbook of research on sustainable careers. Edward Elgar Publishing, 2015.

28. Ehnert I, Harry W. Recent developments and future prospects on sustainable human resource management: Introduction to the special issue $[\mathrm{J}]$. Management revue, 2012: 221-238.

29. Jepsen D M, Grob S. Sustainability in recruitment and selection: building a framework of practices[J]. Journal of Education for Sustainable Development, 2015, 9(2): 160-178.

30. Taylor S , Osland J , Egri C P. Guest editors' introduction: Introduction to HRM's role in sustainability: Systems, strategies, and practices[J]. Human Resource Management, 2012, 51(6):789-798.

31. Guerci M, Pedrini M. The consensus between Italian $\mathrm{HR}$ and sustainability managers on HR management for sustainability-driven change-towards a 'strong'HR management system[J]. The International Journal of Human Resource Management, 2014, 25(13): 1787-1814.

32. Orlitzky M, Swanson D L, Quartermaine L K. Normative myopia, executives' personality, and preference for pay dispersion: Toward implications for corporate social performance[J]. Business \& society, 2006, 45(2): 149-177.

33. Wikhamn W. Innovation, sustainable HRM and customer satisfaction[J]. International Journal of Hospitality Management, 2019, 76: 102-110.

34. Browne M W, Cudeck R. Alternative ways of assessing model fit[J]. Sociological methods \& research, 1992, 21(2): 230-258.

35. Medsker G J, Williams L J, Holahan P J. A review of current practices for evaluating causal models in 
organizational behavior and human resources management research[J]. Journal of management, 1994, 20(2): 439-464.

36. Fornell C, Larcker D F. Evaluating structural equation models with unobservable variables and measurement error[J]. Journal of marketing research, 1981, 18(1): 39-50.
37. Boden S D, Liu Y, Hair G A, et al. LMP-1, a LIM-domain protein, mediates BMP-6 effects on bone formation[J]. Endocrinology, 1998, 139(12): 5125-5134.

38. Bagozzi R P, Yi Y. On the evaluation of structural equation models[J]. Journal of the academy of marketing science, 1988, 16(1): 74-94. 